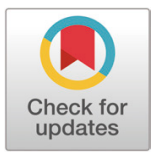

Received: May 12, 2020

Revised: Jun 18, 2020

Accepted: Jul 15, 2020

*Corresponding author In Ho Kim

Department of Animal Resource and Science, Dankook University

Cheonan 31116, Korea.

Tel: +82-41-550-3652

E-mail: inhokim@dankook.ac.kr

Copyright $\odot 2020$ Korean Society of Animal Sciences and Technology. This is an Open Access article distributed under the terms of the Creative Commons Attribution Non-Commercial License (http:// creativecommons.org/licenses/by$\mathrm{nc} / 4.0 /$ ) which permits unrestricted non-commercial use, distribution, and reproduction in any medium, provided the original work is properly cited.

ORCID

Jae Hong Park

https://orcid.org/0000-0002-2025-0141

Shanmugam Sureshkumar

https://orcid.org/0000-0002-3632-3114

In Ho Kim

https://orcid.org/0000-0001-6652-2504

Competing interests

No potential conflict of interest relevant to this article was reported.

Funding sources

The present research was supported by the research fund of Dankook University in 2020 .

Acknowledgements Not applicable.

\section{Influences of dietary flavonoid (quer- cetin) supplementation on growth performance and immune response of growing pigs challenged with Escherichia coli lipopolysaccharide}

\author{
Jae-Hong Park, Shanmugam Sureshkumar and In Ho Kim* \\ Department of Animal Resource and Science, Dankook University, Cheonan 31116, Korea
}

\section{Abstract}

This study was conducted to evaluate the effects of dietary supplementation of plant flavonoid (quercetin) on immune parameters, growth performance, and nutrient digestibility in growing pigs challenged with Escherichia coli lipopolysaccharide (LPS). A total of 40 crossbred ([Landrace $\times$ Yorkshire] $\times$ Duroc) growing pigs; initial body weight (BW) of $26.95 \pm 1.26$ $\mathrm{kg}$ were used in a six-week experimental trial. Pigs were randomly allocated into one of four treatment groups in a $2 \times 2$ factorial arrangement with the following factors; without LPS challenge and with LPS challenge (day 21) supplemented with or without $0.1 \%$ flavonoid according to BW (2 replicate pens per treatment with 2 gilts and 3 barrows per pen). The singledose LPS (100 ug / kg BW) injection showed trends tended to be increased in interleukin-6 (IL-6) after $2 \mathrm{~h}$ and $6 \mathrm{~h}$ of challenge compared with unchallenged pigs. However, other measured immune indices (white blood cell, immunoglobulin G, lymphocyte, and tumor necrosis factor), growth performance, and nutrient digestibility were not significantly different between challenged and non-challenged animals. The supplementation of flavonoid significantly increased $(p<0.05)$ average daily gain (ADG) during day $0-21$, tended to increase dry matter and nitrogen digestibility, significantly reduced IL-6, increased Ig-G and WBC concentrations and increased lymphocytes percentage regardless of LPS challenge.

Keywords: Flavonoid, Growing pigs, Immune stimulation, Lipopolysaccharide

\section{INTRODUCTION}

Pigs raised in the intensive farming program inevitably face several environmental threats that impair homeostasis and increase the likelihood of infectious disease outbreaks. As a result, livestock health and productivity are negatively affected. The magnitude of challenges faced by the animal determines their ability to maintain homeostasis in order to enhance growth, productivity, and health status. Alternative solutions to the management of infectious diseases endemic to commercially farmed pigs, in addition to the use of therapeutics, must be pursued. One of the alternative approaches is to supplement the animal diet with phytobiotics which is considered to be the safest alternatives. 
Availability of data and material Upon reasonable request, the datasets of this study can be available from the corresponding author.

\section{Authors' contributions}

Conceptualization: Park JH, Kim IH. Data curation:, Park JH, Sureshkumar S. Formal analysis: Park JH.

Investigation: Park JH, Shanmugam S, Kim IH. Writing - original draft: Park JH, Sureshkumar S. Writing - review \& editing: Park JH, Kim IH.

Ethics approval and consent to participate The experiment protocols used in the study were approved by the Animal Care and Used Committee of Dankook University (Ethics Approval Number: DK-2-1832).
Plant extracts from different types of plants have a wide range of bioactive compounds that have beneficial health effects [1]. Flavonoids are part of the polyphenol family of phytonutrients and each kind of flavonoid has its distinct range of acts and benefits [2]. They are mostly found in flowers, fruits, vegetables and have beneficial antioxidant effects [3]. In the last few years, a considerable number of studies focused on the effect of flavonoids, such as Spiraea japonica flower are rutin, quercetin, isorhamnetin, genistein and kaempferol, in improving the growth performance and health of livestock [4-6]. Quercetin, the primary flavonoid compound in this study, is one of the most known and characterized flavonoids and is the most common dietary flavonoid [7]. Recently considerable attention has been paid to flavonoid research because of the reported potential beneficial effects on human health which includes anti-inflammatory, antitumor, antiviral, anti-allergic, antiplatelet, antioxidant and immunomodulatory effects [3]. Research studies on laboratory animals have indicated that plant flavonoids inhibited the proliferation of pathogenic micro-organisms thereby enhancing intestinal efficiency, attenuated Escherichia coli lipopolysaccharide (LPS) and enhanced immune responses $[8,9]$. However, there have been few studies responses to growing pigs with a flavonoid (quercetin) under the LPS challenge. Thus, in the present study, our objectives were to evaluate the induction of immune responses with single-dose LPS challenge as well as to evaluate the effect of dietary flavonoid (quercetin) supplementation on the performance and immune responses in both LPS challenged and non-challenged growing pigs.

\section{MATERIALS AND METHODS}

The present experiment was performed at the swine experimental unit of Dankook University (Cheonan, Korea). The Animal Care and Use Committee of Dankook University approved the protocol for the current experiment.

\section{Experimental design, animals, housing and diets}

A total of 40 mixed-sex growing pigs ([Landrace $\times$ Yorkshire $] \times$ Duroc) with an initial body weight $(\mathrm{BW})$ of $26.95 \pm 1.26 \mathrm{~kg}$ (mean $\pm \mathrm{SE})$ were used in a 6-week experimental trial. growing pigs were blocked based on body weight to a $2 \times 2$ factorial arrangement with the respective factors being 1 ) normal saline or $E$. coli LPS injection using a syringe and bluntend catheter 2) Basal diet without flavonoid and basal diet $+0.1 \%$ plant flavonoid (quercetin) the dietary supplementation of flavonoid (quercetin) as the major compound was commercially available (Synergen, Bucheon, Korea). Each treatment consisted of 10 replicate pens with 1 pig per pen. The diets were formulated to meet or exceed [10] NRC, 2012 recommendations for all nutrients (Table 1). The stock solution of bacterial LPS (E. coli, 0111: B4, Sigma, St. Louis, MO, USA) was prepared by dissolving LPS in $0.9 \%$ normal saline to make a concentration of $1 \mathrm{mg} / \mathrm{mL}$ and then stored at $-20^{\circ} \mathrm{C}$ until its use. Twenty pigs were challenged with a single-dose of $100 \mu \mathrm{g} / \mathrm{kg}$ BW intraperitoneal injection of $E$. coli LPS at day 21 during the 6-week experiment. Remaining 20 pigs were intraperitoneally injected with an equal amount of sterilized normal saline $(0.9 \% \mathrm{NaCl})$ which served as a control. Every pig was individually identified by using tags, and pigs were offered ad libitum feed and water, through a self-feeder and nipple drinker respectively.

\section{Sampling and measurements}

The measurement of BW was done on day 0, day 21, day 22 and day 42. To calculate the average daily gain $(\mathrm{ADG})$, average daily feed intake (ADFI) and gain to feed ratio (G:F), the consumption of feed was recorded on a pen basis during the experiment.

To calculate apparent dry matter (DM), nitrogen $(\mathrm{N})$, and energy digestibility, $0.20 \%$ chromium 


\begin{tabular}{lc}
\hline Ingredients (\%) & 73.99 \\
Corn & 21.31 \\
Soybean meal & 1.78 \\
Tallow & 1.24 \\
Tri calcium phosphate & 0.75 \\
Limestone & 0.2 \\
Salt & 0.06 \\
Methionine (99\%) & 0.42 \\
Lysine & 0.1 \\
Mineral mix ${ }^{1)}$ & 0.12 \\
Vitamin mix) & 0.03 \\
Choline (25\%) & \\
Calculated value & 3,300 \\
ME (kcal/kg) & 16.5 \\
Crude protein (\%) & 4.64 \\
Crude fat (\%) & 2.51 \\
Crude fiber (\%) & 1.12 \\
Lysine (\%) & 0.32 \\
Methionine (\%) & 0.66 \\
Calcium (\%) & 0.56 \\
Phosphorous (\%) & 4.52 \\
Ash (\%) & \\
\hline
\end{tabular}

1)Provided per kg diet: $\mathrm{Fe}, 138 \mathrm{mg}$ as ferrous sulfate; $\mathrm{Cu}, 84 \mathrm{mg}$ as copper sulfate; $\mathrm{Mn}, 24 \mathrm{mg}$ as manganese oxide; $\mathrm{Zn}, 72 \mathrm{mg}$ as zinc oxide; $1,0.6 \mathrm{mg}$ as potassium iodide; and $\mathrm{Se}, 0.36 \mathrm{mg}$ as sodium selenite.

${ }^{2)}$ Provided per kilograms of diet: vitamin $\mathrm{A}, 15,600 \mathrm{IU}$; vitamin $\mathrm{D}_{3}, 2,040 \mathrm{IU}$; vitamin $\mathrm{E}, 72 \mathrm{IU}$; vitamin $\mathrm{K}_{3}, 6$ mg; vitamin $\mathrm{B}_{1}, 5.04$ $\mathrm{mg}$; vitamin $\mathrm{B}_{2}, 22.8 \mathrm{mg}$; vitamin $\mathrm{B}_{6}, 8.04 \mathrm{mg}$; vitamin $\mathrm{B}_{12}, 0.06 \mathrm{mg}$; biotin, $0.408 \mathrm{mg}$; folic acid, $2.52 \mathrm{mg}$; niacin, $66 \mathrm{mg}$; D-calcium pantothenate, $54 \mathrm{mg}$.

oxide was added to the diet as an indigestible marker for 7 days prior to fecal collection at $6^{\text {th }}$ week. Fecal samples were collected randomly from at least 2 pigs (1 barrow and 1gilt) from each pen, mixed and pooled and a representative sample was stored in a freezer at $-20^{\circ} \mathrm{C}$ until analyzed. All feed and fecal samples were freeze-dried and finely ground to pass through a $1 \mathrm{~mm}$ screen. DM and $\mathrm{N}$ digestibility were determined using methods established by the Association of Official Analytical Chemists [11]. UV absorption spectrophotometry (UV-1201, Shimadzu, Kyoto, Japan) was used to determine chromium in the diets and feces and Parr 6100 oxygen bomb calorimeter (Parr Instrument, Moline, IL, USA) was used to analyze energy by measuring the heat of combustion in the samples. For the calculation of apparent total tract digestibility following formula was used: digestibility $(\%)=(1-[\{\mathrm{Nf} \times \mathrm{Cd}\} /\{\mathrm{Nd} \times \mathrm{Cf}\}]) \times 100$, where $\mathrm{Nf}=$ nutrient concentration in faeces $(\% \mathrm{DM}), \mathrm{Nd}=$ nutrient concentration in $\operatorname{diet}(\% \mathrm{DM}), \mathrm{Cd}=$ chromium concentration in $\operatorname{diet}(\%$ $\mathrm{DM})$, and $\mathrm{Cf}=$ chromium concentration in faeces $(\% \mathrm{DM})$. The rectal temperature of all animals was recorded at $0 \mathrm{~h}, 2 \mathrm{~h}, 6 \mathrm{~h}$, and $12 \mathrm{~h}$ after LPS or saline injection using a digital thermometer (Center 375 RTD Thermometer, Center technology, Taipei, Taiwan).

For blood profile analysis, 6 pigs per treatment ( 3 pigs/pen), whose initial body weights were close to the median weight, were randomly selected and bled via jugular venipuncture at $0,2,6$, and 12 hours after $E$. coli LPS or saline injection during day 21 of the experiment. To obtain serum and whole blood we collected blood samples into vacuum tubes containing no additive and tubes containing K3EDTA (Becton Dickinson Vacutainer Systems, Franklin Lakes, NJ, USA) respectively. 
An automatic blood analyzer (ADVIA 120, Bayer, Tarrytown, NY, USA) was used to analyze white blood cell (WBC) counts and lymphocyte from whole blood samples. The lymphocytes were then expressed as a percentage of the total WBC. The serum was centrifuged for $15 \mathrm{~min}$ at 3,000 $\times \mathrm{g}$ at $4^{\circ} \mathrm{C}$, and stored at $-4^{\circ} \mathrm{C}$ until the determination of serum immunoglobulin $\mathrm{G}(\mathrm{IgG})$, tumor necrosis factor-alpha (TNF- $\alpha$ ), (R and D Porcine ELISA kit, R and D Systems, Minneapolis, MN, USA), and interleukin 6 (IL-6) (R and D Porcine IL-6 ELISA kit, R and D Systems).

\section{Statistical analysis}

Data were subjected to two-way analysis of variance (ANOVA) according to the factorial design of the study using SAS (SAS Inst., Cary, NC, USA). The experimental unit for this experiment was pen. The SEM was used to express variability in data Tukey's test was used to determine the differences among the treatment means. Probability level of $p<0.05$ was considered a statistically significant and $p<0.1$ was considered tendency.

\section{RESULTS}

The effect of flavonoid (quercetin) on blood metabolites of growing pigs challenged with LPS is presented in Table 2. The concentration of IL-6 tended to be increased at $2 \mathrm{~h}(p=0.077)$ and $6 \mathrm{~h}$

Table 2. Effect of flavonoid on blood profile in LPS challenged growing pig

\begin{tabular}{|c|c|c|c|c|c|c|c|c|}
\hline \multirow{2}{*}{ Items } & \multicolumn{2}{|c|}{ Saline } & \multicolumn{2}{|c|}{ LPS } & \multirow{2}{*}{ SEM } & \multicolumn{3}{|c|}{$p$-value } \\
\hline & -Fla & +Fla & -Fla & +Fla & & LPS effect & Flavonoid effect & Interaction \\
\hline \multicolumn{9}{|l|}{$\mathrm{Oh}$} \\
\hline Lymphocyte (\%) & 34.34 & 34.93 & 38.87 & 37.39 & 2.05 & 0.4944 & 0.0987 & 0.3381 \\
\hline $\lg G\left(10^{3} / \mu \mathrm{L}\right)$ & 273 & 280 & 315 & 308 & 17 & 0.7645 & 0.1203 & 0.5572 \\
\hline \multicolumn{9}{|l|}{$2 \mathrm{~h}$} \\
\hline WBC $\left(10^{3} / \mu \mathrm{L}\right)$ & 14.79 & 17.66 & 14.76 & 16.63 & 0.65 & 0.4054 & 0.0012 & 0.4380 \\
\hline Lymphocyte (\%) & 39.17 & 41.98 & 43.08 & 42.45 & 2.21 & 0.3797 & 0.6590 & 0.4884 \\
\hline $\lg G\left(10^{3} / \mu \mathrm{L}\right)$ & 280 & 340 & 281 & 330 & 19 & 0.8435 & 0.0229 & 0.8203 \\
\hline WBC $\left(10^{3} / \mu \mathrm{L}\right)$ & 18.20 & 17.40 & 17.02 & 17.65 & 0.60 & 0.4178 & 0.8844 & 0.2190 \\
\hline Lymphocyte (\%) & 46.16 & 48.76 & 46.77 & 48.09 & 0.88 & 0.9739 & 0.0379 & 0.4762 \\
\hline $\lg G\left(10^{3} / \mu \mathrm{L}\right)$ & 251 & 318 & 245 & 291 & 16 & 0.3076 & 0.0023 & 0.5383 \\
\hline TNF- $\alpha(\%)$ & 78.7 & 72.8 & 82.2 & 71.1 & 6.0 & 0.8908 & 0.2118 & 0.6937 \\
\hline IL6 (\%) & 75.0 & 65.3 & 80.1 & 73.1 & 3.9 & 0.0994 & 0.0355 & 0.7181 \\
\hline \multicolumn{9}{|l|}{$12 \mathrm{~h}$} \\
\hline $\operatorname{WBC}\left(10^{3} / \mu \mathrm{L}\right)$ & 18.93 & 18.00 & 17.65 & 18.33 & 0.59 & 0.3824 & 0.8129 & 0.1439 \\
\hline Lymphocyte (\%) & 46.70 & 48.66 & 46.69 & 48.77 & 0.85 & 0.9500 & 0.0242 & 0.9437 \\
\hline $\lg G\left(10^{3} / \mu \mathrm{L}\right)$ & 234 & 271 & 237 & 264 & 14 & 0.8739 & 0.0284 & 0.7055 \\
\hline
\end{tabular}

LPS, lipopolysachharide; - Fla, without flavonoid; + Fla, with $0.1 \%$ flavonoid. 
$(p=0.09)$ post LPS injection in challenged animals compared with the non-challenged pigs. Other immune markers such as WBC, lymphocyte, IgG, TNF- $\alpha$, were not significantly different between LPS challenged and non-challenged animals. The dietary supplementation of flavonoid (quercetin) showed a significant reduction $(p<0.05)$ on IL6 concentration at 0,2 , and 6 hours post LPS injection. In addition, lymphocyte concentration was significantly improved $(p<0.05)$ during 6 and $12 \mathrm{~h}$, and also, IgG concentration was higher $(p<0.05)$ during 2,6 , and $12 \mathrm{~h}$ post LPS injections in quercetin supplemented groups compared with non-supplemented pigs regardless of LPS challenge. The rectal temperature was within the normal range in both LPS challenged and non-challenged animals with or without the inclusion of dietary flavonoid (quercetin) (Table 3). The supplementation of quercetin resulted in higher $(p<0.05)$ ADG but the BW, ADFI; G/F remained unaffected during day $0-21$. The $\mathrm{BW}, \mathrm{ADG}, \mathrm{ADFI}, \mathrm{G} / \mathrm{F}$ during day $22-42$ as well as overall experiment period was also not affected significantly. LPS challenge did not significantly affect the growth performance parameters as compared with control (Table 4). The apparent total tract digestibility (ATTD) of DM and $\mathrm{N}$ tended to be higher in pigs receiving flavonoid supplemented diet than those without flavonoid supplemented diet, but ATTD of energy remained unaffected in pigs fed flavonoid

Table 3. Flavonoid on rectal temperature in LPS challenged growing pig

\begin{tabular}{|c|c|c|c|c|c|c|c|c|}
\hline \multirow{2}{*}{ Items } & \multicolumn{2}{|c|}{ Saline } & \multicolumn{2}{|c|}{ LPS } & \multirow{2}{*}{ SEM } & \multicolumn{3}{|c|}{$p$-value } \\
\hline & -Fla & + Fla & -Fla & + Fla & & LPS effect & Flavonoid effect & Interactior \\
\hline \multicolumn{9}{|c|}{ Temperature $\left({ }^{\circ} \mathrm{C}\right)$} \\
\hline $\mathrm{Oh}$ & 39.75 & 39.93 & 40.17 & 39.67 & 0.37 & 0.8394 & 0.6877 & 0.4101 \\
\hline $2 \mathrm{~h}$ & 39.95 & 40.02 & 40.31 & 39.85 & 0.17 & 0.6047 & 0.3137 & 0.1927 \\
\hline $6 \mathrm{~h}$ & 39.84 & 39.98 & 39.86 & 39.79 & 0.16 & 0.5054 & 0.8270 & 0.6349 \\
\hline $12 \mathrm{~h}$ & 39.81 & 39.82 & 39.57 & 39.62 & 0.18 & 0.3662 & 0.9177 & 0.9177 \\
\hline
\end{tabular}

LPS, lipopolysachharide; -Fla, without flavonoid; +Fla, with $0.1 \%$ flavonoid.

Table 4. Effect of flavonoid on growth performance in LPS challenged growing pig

\begin{tabular}{|c|c|c|c|c|c|c|c|c|}
\hline \multirow{2}{*}{ Items } & \multicolumn{2}{|c|}{ Saline (CON) } & \multicolumn{2}{|c|}{ LPS } & \multirow{2}{*}{ SEM } & \multicolumn{3}{|c|}{$p$-value } \\
\hline & -Fla & + Fla & -Fla & + Fla & & LPS effect & Flavonoid effect & Interaction \\
\hline \multicolumn{9}{|c|}{ Body weight (kg) } \\
\hline Initial & 26.96 & 26.95 & 26.94 & 26.94 & 1.01 & 0.9926 & 1.0000 & 0.9963 \\
\hline $21 d$ & 40.96 & 41.49 & 41.04 & 41.47 & 0.93 & 0.9779 & 0.6327 & 0.9619 \\
\hline $22 d$ & 41.04 & 41.38 & 40.65 & 41.40 & 0.87 & 0.8415 & 0.5638 & 0.8247 \\
\hline Finish & 55.64 & 56.19 & 55.36 & 56.15 & 1.12 & 0.8954 & 0.8519 & 0.9152 \\
\hline \multicolumn{9}{|l|}{$0-21 d$} \\
\hline ADG (g) & 667 & 693 & 671 & 692 & 8 & 0.8646 & 0.0465 & 0.7346 \\
\hline ADFI (g) & 1,290 & 1,276 & 1,283 & 1,281 & 27 & 0.9719 & 0.7929 & 0.8470 \\
\hline $\mathrm{G} / \mathrm{F}$ & 0.517 & 0.543 & 0.523 & 0.541 & 0.016 & 0.8837 & 0.2513 & 0.8154 \\
\hline \multicolumn{9}{|l|}{$22 \mathrm{~d}$-finish } \\
\hline ADG $(g)$ & 730 & 740 & 735 & 737 & 20 & 0.9541 & 0.7747 & 0.8452 \\
\hline ADFI (g) & 1,803 & 1,856 & 1,802 & 1,841 & 30 & 0.8084 & 0.2107 & 0.8318 \\
\hline $\mathrm{G} / \mathrm{F}$ & 0.405 & 0.399 & 0.408 & 0.401 & 0.010 & 0.8343 & 0.8397 & 0.9442 \\
\hline \multicolumn{9}{|l|}{ Overall } \\
\hline ADG (g) & 683 & 696 & 684 & 695 & 8 & 1.0000 & 0.2087 & 0.9067 \\
\hline ADFI (g) & 1,503 & 1,522 & 1,499 & 1,517 & 10 & 0.6827 & 0.1319 & 0.9806 \\
\hline $\mathrm{G} / \mathrm{F}$ & 0.454 & 0.458 & 0.456 & 0.458 & 0.005 & 0.7994 & 0.6506 & 0.8785 \\
\hline
\end{tabular}

LPS, lipopolysaccharide; -Fla, without flavonoid; +Fla, with $0.1 \%$ flavonoid; $A D G$, average daily gain; ADFI, average daily feed intake; G/F, gain to feed ratio. 
Table 5. Effect of flavonoid on nutrient digestibility in LPS challenged growing pig

\begin{tabular}{|c|c|c|c|c|c|c|c|c|}
\hline \multirow{2}{*}{ Items (\%) } & \multicolumn{2}{|c|}{ Saline } & \multicolumn{2}{|c|}{ LPS } & \multirow{2}{*}{ SEM } & \multicolumn{3}{|c|}{$p$-value } \\
\hline & -Fla & + Fla & -Fla & + Fla & & LPS effect & Flavonoid effect & Interaction \\
\hline Dry matter & 70.42 & 71.97 & 69.64 & 71.79 & 0.70 & 0.5326 & 0.0572 & 0.6927 \\
\hline Nitrogen & 68.92 & 70.19 & 69.47 & 70.61 & 0.56 & 0.4374 & 0.0972 & 0.9165 \\
\hline Energy & 70.35 & 71.87 & 69.50 & 71.30 & 1.91 & 0.6190 & 0.2755 & 0.9206 \\
\hline
\end{tabular}

LPS, lipopolysachharide; -Fla, without flavonoid; +Fla, with $0.1 \%$ flavonoid.

supplemented diet. There was no significant difference in nutrient digestibility between controls or LPS challenged animals (Table 5).

\section{DISCUSSION}

A wide range of physiological responses is generally expected to be provoked due to inflammatory challenges. The responses to immune challenges include, fever, reduced feed intake, changes in cytokines concentrations, increase in plasma concentration of acute-phase proteins as well as hypothalamic-pituitary-adrenal axis activation [12-15]. In the current study, E. coli LPS challenge was chosen to induce the stimulation of the immune system in pigs kept under commercial conditions and to evaluate the dietary effects of plant flavonoid on immune-related indices, rectal temperature and growth performance of growing pigs challenged with or without LPS.

A study by Wright et al. [14] performed that the stimulation of immune response lasted for less than $24 \mathrm{~h}$ with single-dose LPS administration. Therefore, we evaluated the immune indices and body temperature at $0,2,6$, and $12 \mathrm{~h}$ after single-dose LPS injection at day 21 of the experiment. Results from the present study indicated that intraperitoneal administration of LPS to growing pigs did not have a significant effect on body temperature as well as pro-inflammatory cytokine, and immune-related indices such as WBC count, lymphocyte percentage, IgG, and TNF- $\alpha$ concentration; although a trend in increase in IL-6 concentration was observed after 0,2 , and $6 \mathrm{~h}$ of LPS injection.

In a review, Tanaka et al. [16] noted that infections and tissue injuries induce acute phase responses as a host defense mechanism resulting in IL-6 production. The trend in the increased concentration in IL-6 after 2 and $6 \mathrm{~h}$ of LPS challenge in the present study indicates that the LPS challenge had a very mild effect in stimulating the acute phase immune response. In contrast to the present finding, elevation in body temperature following the intraperitoneal administration of 100 $\mu \mathrm{g} / \mathrm{kg}$ BW LPS in weaned pigs has been reported Wright et al. [14] \& Johnson \& Bore [12]. In addition, increased plasma TNF- $\alpha$ concentration increased WBC counts and reduction in lymphocyte percentage has been reported with LPS challenge [17,18]. Similarly, LPS injection has been reported to induce the production of $\operatorname{IgG}[19]$. Previous studies also noted that LPS immune challenge caused growth reduction by depression in feed intake $[14,20]$ which is inconsistent with the present study findings. The failure to observe the significant immune stimulation response as well as reduced growth performance in the present study may probably due to a single-dose LPS challenge since some studies noted that immune stimulation is activated by multiple low-dose LPS treatment Upadhaya et al. [21] \& Zhong et al. [18] or it may be due to the route of LPS injection administration, presence of protein impurities in LPS preparation or variation in serotypes used in different studies $[22,23]$. Although E.coli LPS O111:B4 is the most frequently used in porcine research Williams et al. [24]; however, the presence of protein impurities in those LPS preparations may affect the immune stimulation responses [25,26]. Moreover, it has been reported that WHO still accepts a 50\% to $200 \%$ variation from the mean value in the well-accepted Limulus amebocyte lysate test [27].

In the earlier study, $\mathrm{Li}$ et al. [28] stated that in vivo animal studies with quercetin were found to 
demonstrate an anti-inflammatory effect. It has been shown that quercetin inhibits LPS-induced TNF- $\alpha$ production in macrophages and block IL-6 secretion [29,30]. In the present study also, it was found that supplementation of quercetin to the diet of pigs' significantly reduced IL-6 concentration at 2, 6, and $12 \mathrm{~h}$ after LPS/saline injection. In addition, WBC counts, IgG concentration and lymphocyte percentage were positively influenced in the present study by quercetin supplementation regardless of LPS challenge. Quercetin acts mainly on leukocytes and targets many enzymes and membrane proteins, intracellular signaling kinases and phosphatases, which are often crucial for a cellular specific function thereby affecting immunity and inflammation. For instance, LPS-induced inflammation is reduced by inhibiting Src- and Syk-mediated phosphatidylinositol-3-kinase (PI3K)- (p85) tyrosine phosphorylation [31].

In poultry study, Liu et al. [32] demonstrated that that intermediate levels $(0.2-0.4 \mathrm{~g} / \mathrm{kg}$ feed $)$ of quercetin supplementation improved feed efficiency in hens, but higher levels $(0.6 \mathrm{~g} / \mathrm{kg}$ feed $)$ had a negative effect. Similarly, Goliomytis et al. [33] found relatively high inclusion levels caused a non-significant increase in the feed conversion ratio (FCR) of broiler chickens. In the present study, except for an increase in ADG during day 0-21, none of the other growth performance parameters were affected by $0.1 \%$ quercetin supplementation in growing pigs. A trend in increase in the DM and $\mathrm{N}$ digestibility with quercetin supplementation seen in the present study might be due to the alteration of the intestinal microbiota resulting in lower systemic inflammation and improved metabolic outcomes [34]. A tendency in nutrient digestibility might had a positive effect on ADG before the LPS challenge but no effect on ADG after LPS challenge was observed. The inconsistent findings among different studies on growth performance might probably due to the dose of quercetin, animal species as well as diet types. There were no interactive effects between LPS injection and flavonoid (quercetin) supplementation in any of the measured parameters.

\section{CONCLUSION}

Taken together, there was short term mild stimulation of inflammation by single-dose LPS challenge which was indicated by a trend in the increase in plasma IL-6 concentration at 2 and $6 \mathrm{~h}$ after LPS injection, although other measured immune-related parameters were not triggered. The supplementation of quercetin to the diet enhanced immune function regardless of LPS challenge by reducing IL-6 concentration and increasing Ig-G, WBC and lymphocytes. The digestibility of $\mathrm{DM}$ and $\mathrm{N}$ tended to increase that might have increased the ADG of non-challenged animals. Therefore, further investigations are needed to evaluate the purified LPS injection and the supplementation of flavonoid (quercetin) at different doses to the LPS challenged animals.

\section{REFERENCES}

1. Vidanarachchi JK, Mikkelsen LL, Sims I, Iji PA, Choct M. Phytobiotics: alternatives to antibiotic growth promoters in monogastric animal feeds. Recent Adv Anim Nutr Aust. 2005;15:131-44.

2. Hodek P, Trefil P, Stiborová M. Flavonoids-potent and versatile biologically active compounds interacting with cytochromes P450. Chem Biol Interact. 2002;139:1-21. https://doi. org/10.1016/S0009-2797(01)00285-X

3. Agrawal AD. Pharmacological activities of flavonoids: a review. Int J Pharm Sci Nanotechnol. 2011;4:1394-8. https://doi.org/10.37285/ijpsn.2011.4.2.3

4. Kim JM, Yun-Choi HS. Anti-platelet effects of flavonoids and flavonoid-glycosides from Sophora japonica. Arch Pharm Res. 2008;31:886-90. https://doi.org/10.1007/s12272-001-1242-1 
5. Zhu C, Wu Y, Jiang Z, Zheng C, Wang L, Yang X, et al. Dietary soy isoflavone attenuated growth performance and intestinal barrier functions in weaned piglets challenged with lipopolysaccharide. Int Immunopharmacol. 2015;28:288-94. https://doi.org/10.1016/j.intimp.2015.04.054

6. Ma T, Chen DD, Tu Y, Zhang NF, Si BW, Diao QY. Dietary supplementation with mulberry leaf flavonoids inhibits methanogenesis in sheep. Anim Sci J. 2017;88:72-8. https://doi. org/10.1111/asj.12556

7. Erlund I. Review of the flavonoids quercetin, hesperetin, and naringenin. Dietary sources, bioactivities, bioavailability, and epidemiology. Nutr Res. 2004;24:851-74. https://doi.org/10.1016/ j.nutres.2004.07.005

8. Calixto JB, Campos MM, Otuki MF, Santos ARS. Anti-inflammatory compounds of plant origin. Part II. modulation of pro-inflammatory cytokines, chemokines and adhesion molecules. Planta Med. 2004;70:93-103. https://doi.org/10.1055/s-2004-815483

9. Kawaguchi K, Kikuchi SI, Hasunuma R, Maruyama H, Yoshikawa T, Kumazawa Y. A citrus flavonoid hesperidin suppresses infection-induced endotoxin shock in mice. Biol Pharm Bull. 2004;27:679-83. https://doi.org/10.1248/bpb.27.679

10. NRC [National Research Council]. Nutritional requirements for swine. 11th ed. Washington DC: The National Academies Press; 2012.

11. AOAC [Association of Official Analytical Chemists] International. Official methods of analysis of AOAC International. 16th ed. Washington DC: AOAC International; 2000.

12. Johnson RW, von Borell E. Lipopolysaccharide-induced sickness behavior in pigs is inhibited by pretreatment with indomethacin. J Anim Sci. 1994;72:309-14. https://doi. org/10.2527/1994.722309x

13. Curfs JH, Meis JF, Hoogkamp-Korstanje JA. A primer on cytokines: sources, receptors, effects, and inducers. Clin Microbiol Rev. 1997;10:742-80. https://doi.org/10.1128/CMR.10.4.742

14. Wright KJ, Balaji R, Hill CM, Dritz SS, Knoppel EL, Minton JE. Integrated adrenal, somatotropic, and immune responses of growing pigs to treatment with lipopolysaccharide. J Anim Sci. 2000;78:1892-9. https://doi.org/10.2527/2000.7871892x

15. Rakhshandeh A, Htoo JK, Karrow N, Miller SP, De Lange CFM. Impact of immune system stimulation on the ileal nutrient digestibility and utilisation of methionine plus cysteine intake for whole-body protein deposition in growing pigs. Br J Nutr. 2014;111:101-10. https://doi. org/10.1017/S0007114513001955

16. Tanaka T, Narazaki M, Kishimoto T. IL-6 in inflammation, immunity, and disease. Cold Spring Harb Perspect Biol. 2014;6:a016295. https://doi.org/10.1101/cshperspect.a016295

17. Webel DM, Finck BN, Baker DH, Johnson RW. Time course of increased plasma cytokines, cortisol, and urea nitrogen in pigs following intraperitoneal injection of lipopolysaccharide. J Anim Sci. 1997;75:1514-20. https://doi.org/10.2527/1997.7561514x

18. Zhong Y, Zhang X, Hu X, Li Y. Effects of repeated lipopolysaccharide treatment on growth performance, immune organ index, and blood parameters of Sprague-Dawley rats. J Vet Res. 2018;62:341-6. https://doi.org/10.2478/jvetres-2018-0048

19. Kim MH, Yun CH, Kim GR, Ko JY, Lee JJ, Ha JK. Changes of immunoglobulins and lymphocyte subpopulations in peripheral blood from Holstein calves challenged with Escherichia coli lipopolysaccharide. Asian-Australas J Anim Sci. 2011;24:696-706. https://doi.org/10.5713/ ajas.2011.11029

20. Dritz SS, Owen KQ, Goodband RD, Nelssen JL, Tokach MD, Chengappa MM, et al. Influence of lipopolysaccharide-induced immune challenge and diet complexity on growth performance and acute-phase protein production in segregated early-weaned pigs. J Anim Sci. 
1996;74:1620-8. https://doi.org/10.2527/1996.7471620x

21. Upadhaya SD, Kim JC, Mullan BP, Pluske JR, Kim IH. Vitamin E and omega-3 fatty acids independently attenuate plasma concentrations of proinflammatory cytokines and prostaglandin E2 in Escherichia coli lipopolysaccharide-challenged growing-finishing pigs. J Anim Sci. 2015;93:2926-34. https://doi.org/10.2527/jas.2014-8330

22. Dogan MD, Ataoglu H, Akarsu ES. Effects of different serotypes of Escherichia coli lipopolysaccharides on body temperature in rats. Life Sci. 2000;67:2319-29. https://doi.org/10.1016/ S0024-3205(00)00821-3

23. Doğan MD, Ataoğlu H, Akarsu ES. Characterization of the hypothermic component of LPS-induced dual thermoregulatory response in rats. Pharmacol Biochem Behav. 2002;72:14350. https://doi.org/10.1016/S0091-3057(01)00736-5

24. Williams PN, Collier CT, Carroll JA, Welsh TH, Laurenz JC. Temporal pattern and effect of sex on lipopolysaccharide-induced stress hormone and cytokine response in pigs. Domest Anim Endocrinol. 2009;37:139-47. https://doi.org/10.1016/j.domaniend.2009.04.004

25. Lorne E, Dupont H, Abraham E. Toll-like receptors 2 and 4: initiators of non-septic inflammation in critical care medicine? Intensive Care Med. 2010; 36:1826-35. https://doi. org/10.1007/s00134-010-1983-5

26. Rutledge HR, Jiang W, Yang J, Warg LA, Schwartz DA, Pisetsky DS, et al. Gene expression profiles of RAW264.7 macrophages stimulated with preparations of LPS differing in isolation and purity. Innate Immun. 2012;18:80-8. https://doi.org/10.1177/1753425910393540

27. Fingola FF, Albertino SRG, Abrantes S de MP, Zamith HPS. Intralaboratory validation of kinetic chromogenic Limulus amebocyte lysate assay for bacterial endotoxin determination in anti-bothropic serum. J Pharm Biomed Anal. 2013;85:93-8. https://doi.org/10.1016/j.jpba.2013.06.034

28. Li Y, Yao J, Han C, Yang J, Chaudhry MT, Wang S, et al. Quercetin, inflammation and immunity. Nutrients. 2016;8:167. https://doi.org/10.3390/nu8030167

29. Rao MK, Ghosh B. Quercetin inhibits LPS-induced nitric oxide and tumor necrosis factor- $\alpha$ production in murine macrophages. Int J Immunopharmacol. 1999;21:435-43. https://doi. org/10.1016/S0192-0561(99)00024-7

30. Kandere-Grzybowska K, Kempuraj D, Cao J, Cetrulo CL, Theoharides TC. Regulation of IL1-induced selective IL-6 release from human mast cells and inhibition by quercetin. $\mathrm{Br} \mathrm{J}$ Pharmacol. 2006;148:208-15. https://doi.org/10.1038/sj.bjp.0706695

31. Endale M, Park SC, Kim S, Kim SH, Yang Y, Cho JY, et al. Quercetin disrupts tyrosine-phosphorylated phosphatidylinositol 3-kinase and myeloid differentiation factor-88 association, and inhibits MAPK/AP-1 and IKK/NF- $\kappa$ B-induced inflammatory mediators production in RAW 264.7 cells. Immunobiology. 2013;218:1452-67. https://doi.org/10.1016/j.imbio.2013.04.019

32. Liu HN, Liu Y, Hu LL, Suo YL, Zhang L, Jin F, et al. Effects of dietary supplementation of quercetin on performance, egg quality, cecal microflora populations, and antioxidant status in laying hens. Poult Sci. 2014;93:347-53. https://doi.org/10.3382/ps.2013-03225

33. Goliomytis M, Tsoureki D, Simitzis PE, Charismiadou MA, Hager-Theodorides AL, Deligeorgis SG. The effects of quercetin dietary supplementation on broiler growth performance, meat quality, and oxidative stability. Poult Sci. 2014;93:1957-62. https://doi.org/10.3382/ ps.2013-03585

34. Kawabata K, Mukai R, Ishisaka A. Quercetin and related polyphenols: new insights and implications for their bioactivity and bioavailability. Food Funct. 2015;6:1399-417. https://doi. org/10.1039/C4FO01178C 